\title{
APPLICATION OF MICROGRAVITY AND ELECTRICAL RESISTIVITY IMAGING TECHNIQUES TO IDENTIFY GROUND SUBSIDENCE PRONE ZONE
}

\author{
Mustapha Adejo MOHAMMED ${ }^{1,2)}$, Nordiana MOHD MUZTAZA ${ }^{1)}$ *, Muhammad SABIU BALA ${ }^{3)}$, \\ Fouzie Mohamed ALMGTOF TREPIL ${ }^{1)}$, Rosli SAAD ${ }^{1)}$, Fauziah AHMAD ${ }^{1)}$ and Yasir BASHIR ${ }^{1)}$
}

\author{
1) Geophysics Section, Universiti Sains Malaysia, Malaysia \\ 2) Department of Physics, Federal University of Lafia, Nigeria \\ ${ }^{3)}$ Department of Physics, Usman Danfodio University Sokoto, Nigeria
}

*Corresponding author's e-mail: mmnordiana@usm.my

\begin{tabular}{l} 
ARTICLE INFO \\
\hline Article history: \\
Received 17 November 2020 \\
Accepted 15 March 2021 \\
Available online 7 April 2021 \\
\hline
\end{tabular}

Keywords:

Subsidence

Microgravity

Resistivity imaging

Subsurface

Pakistan

\begin{abstract}
Owing to the disastrous consequences of ground subsidence in the urban area, great attention had always been accorded to areas with suspected signs of subsidence occurrence in order to mitigate its effect. Microgravity and electrical resistivity imaging (ERI) survey techniques were conducted at a parking lot of which possible occurrence of subsidence is anticipated due to the increased exposure of surface cracks and very slight depression. This study aimed to map and delineate the subsurface condition of the area with the view of revealing probable subsidence prone zones within the study area. To this end, the microgravity survey data was acquired at a station interval of $2 \mathrm{~m}$. Pole-dipole configuration with $2 \mathrm{~m}$ electrode separation was adopted for the electrical resistivity imaging survey. The two methods showed good correlation with each other and proved their effectiveness in imaging the subsurface. A large proportion of the subsurface area was found to be residual soil (mainly silt and or clayey sand) with saturated zones identified by low gravity $(<-40.94 \mathrm{mGal})$ and resistivity $(<150 \Omega . \mathrm{m})$ values, which have the tendency to undergo expansion and contraction processes due to rise and fall in moisture content. The subsurface condition was found to be relatively stable, devoid of any subsidence triggering features such as voids or cavities. However, it is inferred to be unsuitable for engineering structures due to the expansive and contractive properties of the subsurface geomaterials (residual soil). Therefore, it is concluded that the area is not prone to subsidence and the surface cracks presents are mere effects of the expansion and contraction process, which could be avoided by the excavation of the expansive soil or good engineering design before the establishment of any structure.
\end{abstract}

\section{INTRODUCTION}

Ground subsidence is a global geohazard phenomenon that involves gradual downward settling or sudden sinking of the Earth's surface at a regional or local scale (Bell et al., 2005). Both natural processes (e.g. soil compaction, development of subterranean voids by the solution of host rocks, tectonic and volcanic activities) and anthropogenic activities (e.g. subsurface mining, tunnel construction and extraction of groundwater) are known to be the principal causes of subsidence (Cárdenas-Soto et al., 2020; Marschalko et al., 2015). The aftermath of ground subsidence is often disastrous, especially in the urban area. It usually leads to injury or loss of lives, a decrease in water quality, extensive damage to the surface and subsurface structures such as buildings, roads, pipelines, underground tunnels (Cao et al., 2020; Hussain et al., 2020; Salehi et al., 2019). Due to the frequent occurrence of subsidence and its significant impact on lives and properties, it has gained the great attention of researchers globally (Pradhan et al., 2014).
A concerted effort has been made by several researchers to explore related aspects on ground subsidence (Abidin et al., 2013; Ghazifard et al., 2017). The most examined aspects are; monitoring of the subsidence and its prediction. Remote sensing (RS) and geographic information system (GIS) techniques are mostly employed for ground subsidence study because of their efficiency in data collection, analysis and validation (Oh and Lee, 2010; Zheng et al., 2013). However, both techniques are deficient, as they are constraint to surface features only. To have a better understanding of the source of the subsidence, its monitoring and prediction, subsurface information is often required.

Near-surface geophysical techniques such as Microgravity Imaging, Electrical Resistivity Imaging, Ground Penetrating Radar, Seismic Refraction and Ambient Noise Tomography offer a solution to the aforementioned limitation of RS and GIS techniques (Cárdenas-Soto et al., 2020; Martínez-Moreno et al. 2013; Sastry and Mondal, 2013). Quite a number of 

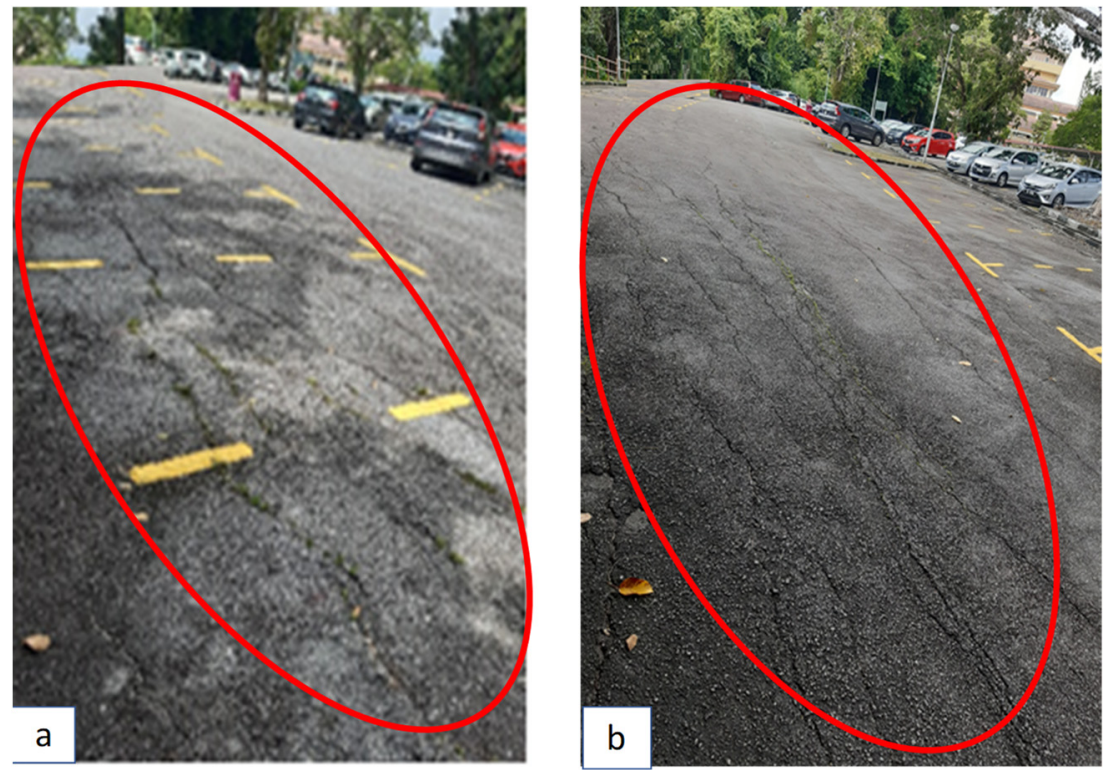

Fig. 1 Site photos of the parking lots, the red circles indicate (a) series of cracks (b) cracks with a slight depression.

researchers employed the geophysical techniques to study subsidence. Yassin et al. (2013) conducted a geohazard assessment of karst features (sinkholes, caves, cavities) using electrical resistivity imaging (ERI) at two complex construction sites in the north of Ipoh, Perak, Malaysia. The result shows the effectiveness of the method in delineating or mapping the subsurface as it revealed low resistive anomalies for the suspected sinkholes and predicts the likely occurrence of subsidence at one of the construction sites. Pazzi et al. (2018) integrated microgravity, electrical resistivity imaging (ERI) and seismic techniques to delineate sinkhole-prone areas for susceptibility assessment and risk mitigation. They found that the area is characterized by paleochannels and that the sinkhole-prone area corresponds to these paleochannels. More so, an integrated study using self-potential, electrical resistivity imaging (ERI), and frequency-domain electromagnetic was successfully carried out to characterize urban subsidence in Butte, Montana, U.S.A. (Prudhomme et al., 2019). In the case study by (Sastry and Mondal, 2013), they employed microgravity, induced polarization imaging and electrical resistivity imaging to detect Salna sinking zones at Garhwal Himalaya, India. The authors inferred the existence of several vertical to sub-vertical faults, and that the sinking of Salna village is along these inferred faults.

Furthermore, Martínez-Moreno et al. (2015) tested the applicability of microgravity and ERI techniques for subsurface cave detection in the gypsum karst system of Sorbas (SE Spain). They found the techniques to be effective in imaging the subsurface. The increased appearance of surface cracks and slight depression at some part of the parking lots (Fig. 1) has no doubt instilled fear in the mind of the residents about the possible occurrence of subsidence. In view of this, the assessment of subsurface features (such as voids, cavities, faults) capable of igniting or triggering the occurrence of ground subsidence is very paramount in order to forestall the catastrophic consequences of either loss of lives or economic losses or both. Hence, the present study is necessitated with the goal to make known the subsurface condition of the area and to delineate zones or areas vulnerable to subsidence. To achieve this goal, microgravity imaging and ERI surveys were conducted at the parking lots. The choice for these methods employed stem from their efficacy in mapping the subsurface as stated in various literatures. The findings of this study will significantly reduce the impact associated with subsidence in the area by updating the area's risk zoning or deploying appropriate engineering design or technique.

\section{METHODOLOGY}

\section{STUDY AREA AND GEOLOGICAL SETTING}

The study area, a parking lot at Universiti Sains Malaysia (USM), Penang Island Malaysia, is located between latitude $5^{\circ} 21^{\prime} 33.12^{\prime \prime}$ to $5^{\circ} 21^{\prime} 36.36^{\prime \prime} \mathrm{N}$ and longitudes $100^{\circ} 18^{\prime} 21.96^{\prime \prime}$ to $100^{\circ} 18^{\prime} 23.76^{\prime \prime} \mathrm{E}$. The geological setting of the island is relatively homogeneous as it is dominated by granitic rock (Kong, 1994). The island is divided mainly into two groups; the North Penang Pluton (NPP) and the South Penang Pluton (SPP). The NPP is dominated by Type I granite, which is made up of orthoclase to intermediate microcline granite, while the SPP is dominated by Type II granite, which is mainly microcline granite (Ahmad et al., 2006; Kong, 1994). The study area belongs to the South Penang Pluton, which is of late Carboniferous age. It composed of fined grained biotite and medium to coarse-grained biotite granite (Ali et al., 2011; Pradhan and Lee, 

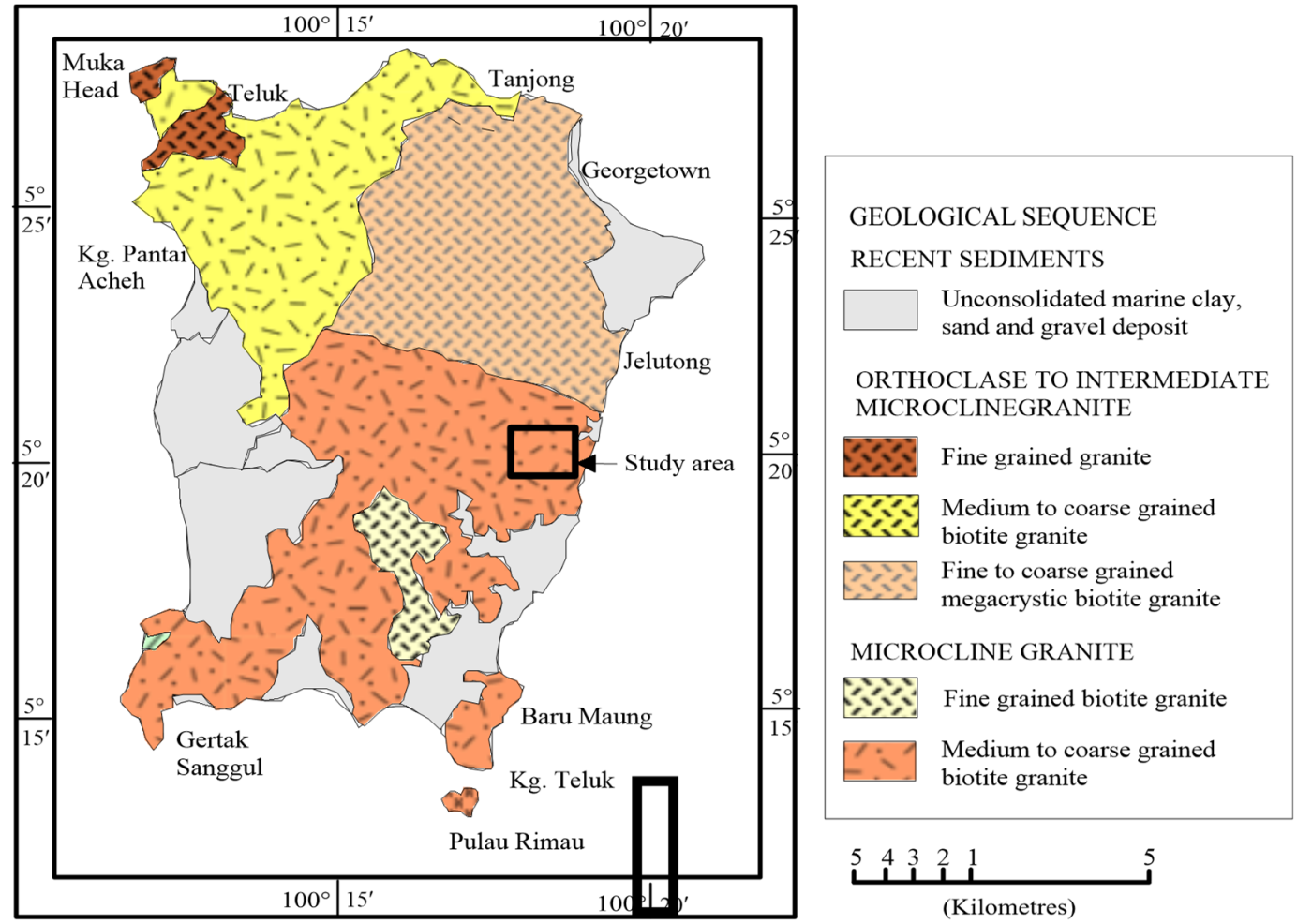

Fig. 2 Geology map of Penang Island modified from (Kong, 1994).

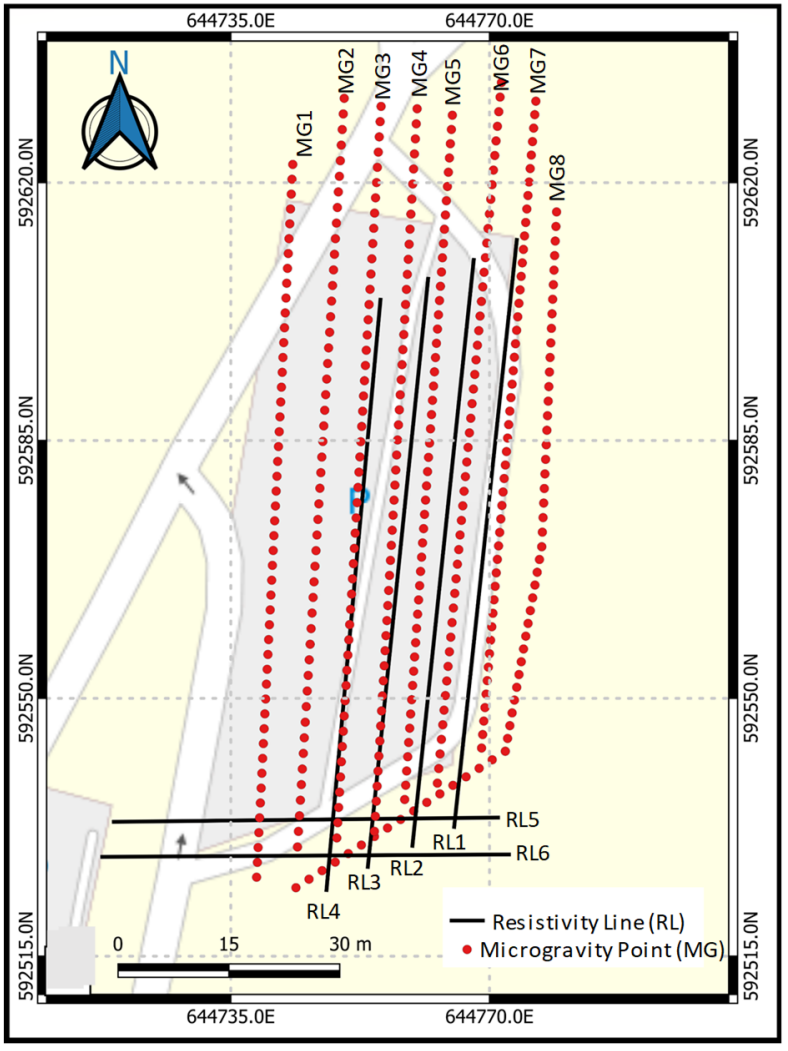

Fig. 3 Profile layout for the survey. The black solid line represents the resistivity line while the small red circles represent the microgravity measurement point.
2010). The geology map of Penang Island showing the study area is shown in Figure 2.

\section{METHODOLOGY}

The subsurface condition of the parking lots was examined by microgravity and electrical resistivity imaging techniques. The survey layout adopted for both techniques are as shown in Figure 3.

\section{MICROGRAVITY}

Microgravity technique enable the effective delineation and detection of small subsurface density contrast with high accuracy by measuring the variation of the gravitational acceleration of the earth (Pazzi et al., 2018). The high sensitivity of the technique made it suitable for this study and other various applications. The presence of subsidence triggering features such as cavities or voids are mostly associated with short-wavelength which constitutes a decrease in the density with respect to the host rock and, thus in the gravity value (Martínez-Moreno et al., 2013).

The microgravity survey was conducted using the Scintrex CG-5 gravity meter. The sensing element of the CG-5 gravimeter is based on a fused quartz elastic system (Scintrex Ltd., 2012). The CG-5 meter has a resolution of $0.001 \mathrm{mGal}$ which made it suitable for both detailed field investigations and large scale regional or geodetic surveys (Scintrex Ltd., 2012). A total of 387 microgravity measurement stations were established on eight survey profiles 
(MG1-MG8). The measurements were made at $2 \mathrm{~m}$ station interval along the profile lines. Seven profiles (profiles MG1-MG7) had a Northeast-Southwest orientation and one (profile MG8) had NortheastSouthwest and North-South orientation (Fig. 3). At each station, three repeated measurements were made in order to enhance the signal-to-noise ratio. The instrument drift was taken into account by establishing a base station which was visited and measured at the beginning and end of each profile line. The acquired microgravity data was subjected to the standard gravity corrections such as drift correction, latitude correction, free-air correction, Bouguer correction and removal of the regional field to obtain residual Bouguer gravity anomaly. Details on each of the corrections can be obtained in Hackney (2020) and Li and Götze (2001).

The RBGA is further subjected to a tilt angle derivative filter (TDR) using Geosoft software (Oasis Montaj v. 8.4). It has been established that TDR is effective in mapping basement structures, edge detection, and mineral exploration (Ibraheem et al., 2018). The filter is defined as in Equation 1.

$T D R=\tan ^{-1}\left(\frac{V D R}{T H D R}\right)$

where VDR is the vertical derivative and THDR is the total horizontal derivatives (Saada, 2016). The advantage of the filter is that it does not require any parameter such as density, structural index, inclination and deflection angle, etc. for its computation (Akin et al., 2011). In general, it is useful as a complementary tool in the structural interpretation of the subsurface geomaterials, as it allows the identification of anomalies with low and high amplitude. As reported by Cárdenas-Soto et al. (2020), the TDR filter tends to constraint the amplitude of potential field to values ranging from $-\pi / 2$ to $+\pi / 2$.

\section{ELECTRICAL RESISTIVITY IMAGING (ERI)}

For the electrical resistivity imaging (ERI) survey, measurements were made using ABEM Terrameter SAS4000 instrument, which injects electric current $(I)$ into the earth through a pair of stainless-steel electrodes and measures the potential difference $(\nabla V)$ through the other pairs of stainlesssteel electrodes. Pole-dipole array configuration with an electrode spacing of $2 \mathrm{~m}$ was employed for the measurement. The configuration was chosen because of its good horizontal coverage and low distortion of equipotential surfaces (Loke, 2018; Smith, 1986). The measured apparent resistivity $\left(\rho_{a}\right)$ of the configuration is written as in Equation 2.

$\rho_{a}=2 \pi n(n+1) a \frac{\nabla V}{I}$

where $\nabla V$ is the potential difference, $I$ is the electric current, $a$ is the electrode spacing and $n$ is the data level.

Six resistivity profile lines (RL1-RL6) were established within and outside the microgravity acquired area. Profiles RL1-RL4 were $80 \mathrm{~m}$ long, oriented in Northeast to Southwest direction whereas profiles RL5 and RL6, oriented in West to East direction are $52 \mathrm{~m}$ and $55 \mathrm{~m}$ long respectively. The acquired ERI data was subjected to filtering processes (such as the extermination of bad data point and root mean square error statistics) as recommended by Loke (2018). Thereafter, inversion of the data was carried out using Res2Dinv software (v. 3.56, Geotomo Inc.). Based on the geological setting of the study area, sharp discontinuities are not expected, as such, the smoothness-constrained leastsquare inversion method was employed. The inversion process tries to produce a better model by minimizing the root mean square (RMS) error value after each iteration.

\section{RESULTS AND DISCUSSION}

The result and discussion of the study outcome are presented in line with the methodology.

\section{MICROGRAVITY}

In microgravity result, low (negative) gravity anomalies are usually caused by low-density zones such as voids or soil with high void ratios or low compactness (clay and silt). The pattern or size of a void-induced gravity anomaly is dependent on the source of the void and its connectivity with the surrounding host rock (Pazzi et al., 2018). Figure 4a depicts a residual Bouguer anomaly (BA) map with values ranging from $-41.27 \mathrm{mGal}$ to $-38.47 \mathrm{mGal}$. The South-East (SE) part of the study area is dominated with low Bouguer anomaly values (-41.27 to $-40.99 \mathrm{mGal})$ as compared to the remaining part of the survey area with relatively higher values (-40.94 to $-38.47 \mathrm{mGal})$. This implies that the southeastern part of the study area consists of low-density geomaterials, which are inferred to be residual soil saturated with water.

The subsurface image was further enhanced by the tilt angle derivative (TDR) as shown in Figure 4b. Upon the application of the TDR filter, the edge of the subsurface features was accentuated, as the low amplitude gravity zones area of coverage increases. The subsurface area with low amplitude negative gravity anomaly values $(-1.50$ to $-1.37 \mathrm{rad})$ corresponds to the areas with surface cracks exposure at the parking lot. Hence the low amplitude negative anomaly zones ( -1.50 to $-1.37 \mathrm{rad})$ are inferred to be a residual soil saturated with water.

\section{ELECTRICAL RESISTIVITY IMAGING (ERI)}

Figure 5 shows the inverse resistivity models of the six 2-D electrical resistivity imaging profiles (RL1-RL6) obtained after five (5) iterations with RMS error of $7.3 \%-8.5 \%$. The resistivity values obtained ranges from $0 \Omega . \mathrm{m}-9000 \Omega . \mathrm{m}$ with a maximum depth of $28 \mathrm{~m}$ for profiles RL1-RL4, whereas $19 \mathrm{~m}$ for profiles RL5-RL6. In analyzing the resistivity result, reference was made to a nearby borehole which provided the lithological information 

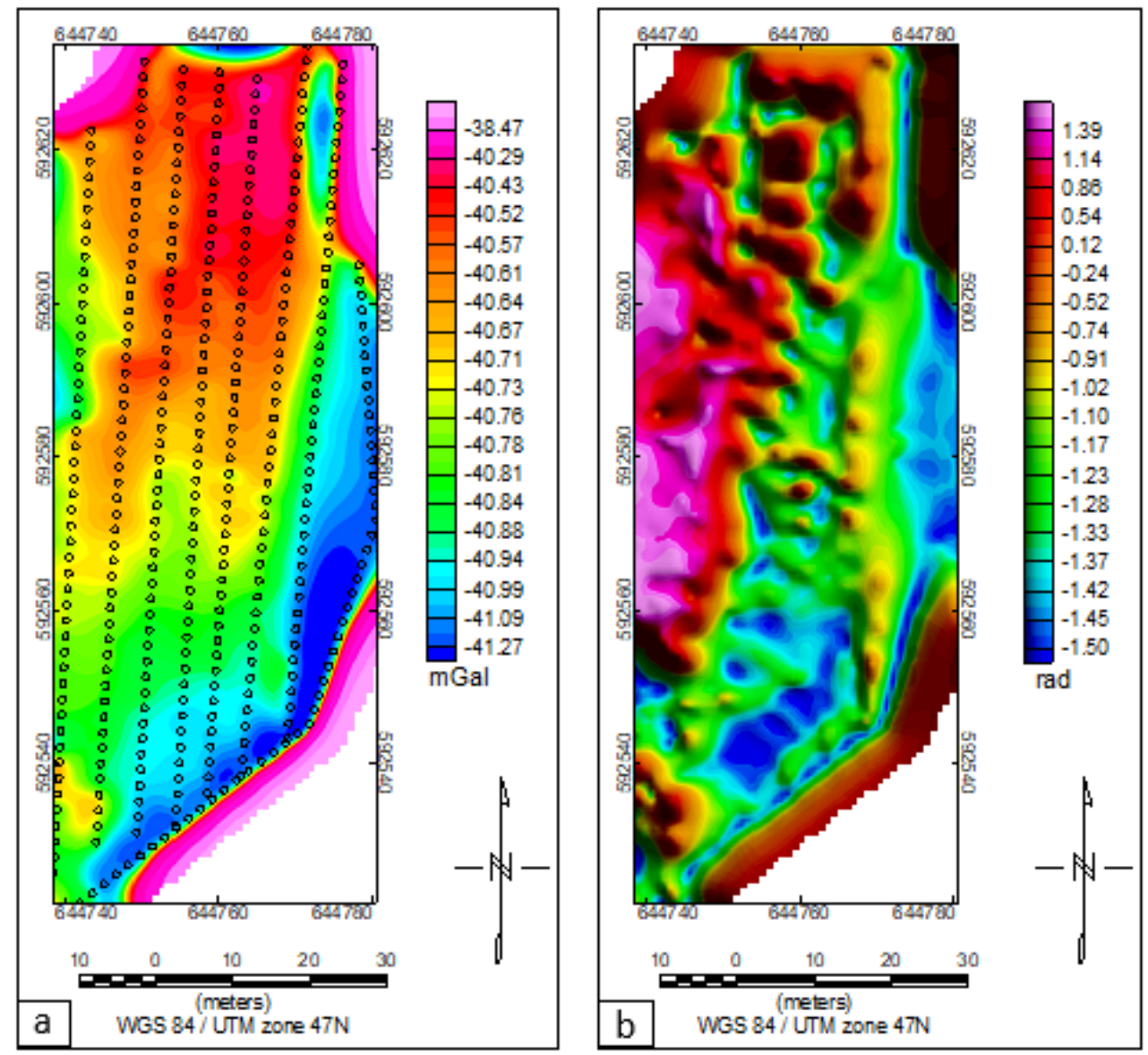

Fig. 4 (a) Bouguer anomaly map with small circles which indicate the microgravity observation point (b) Tilt angle derivative map.
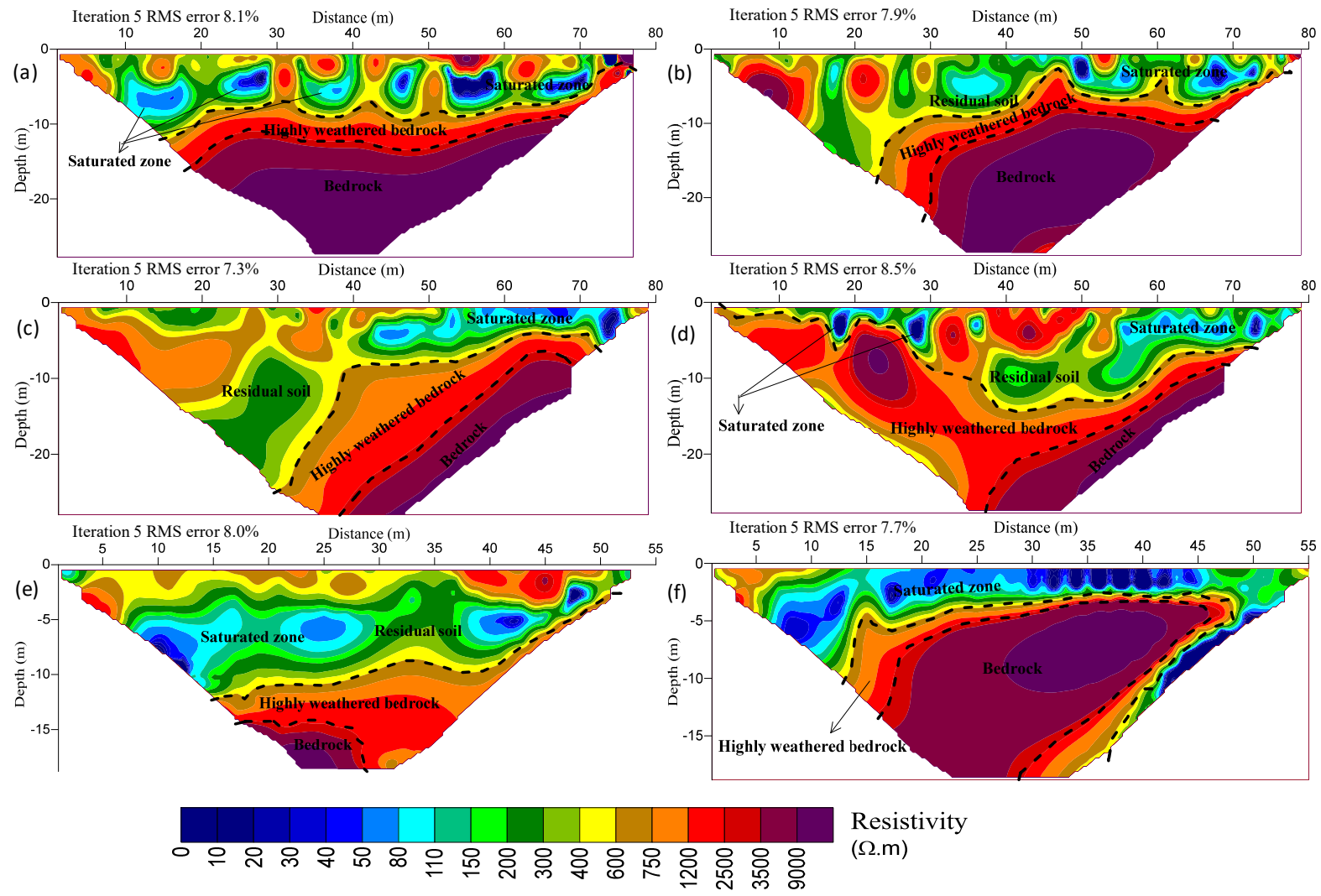

Resistivity

( $\Omega$.m)

Fig. 5 Inverse resistivity models for the six profile lines (a) RL1 (b) RL2 (c) RL3 (d) RL4 (e) RL5 (f) RL6. 


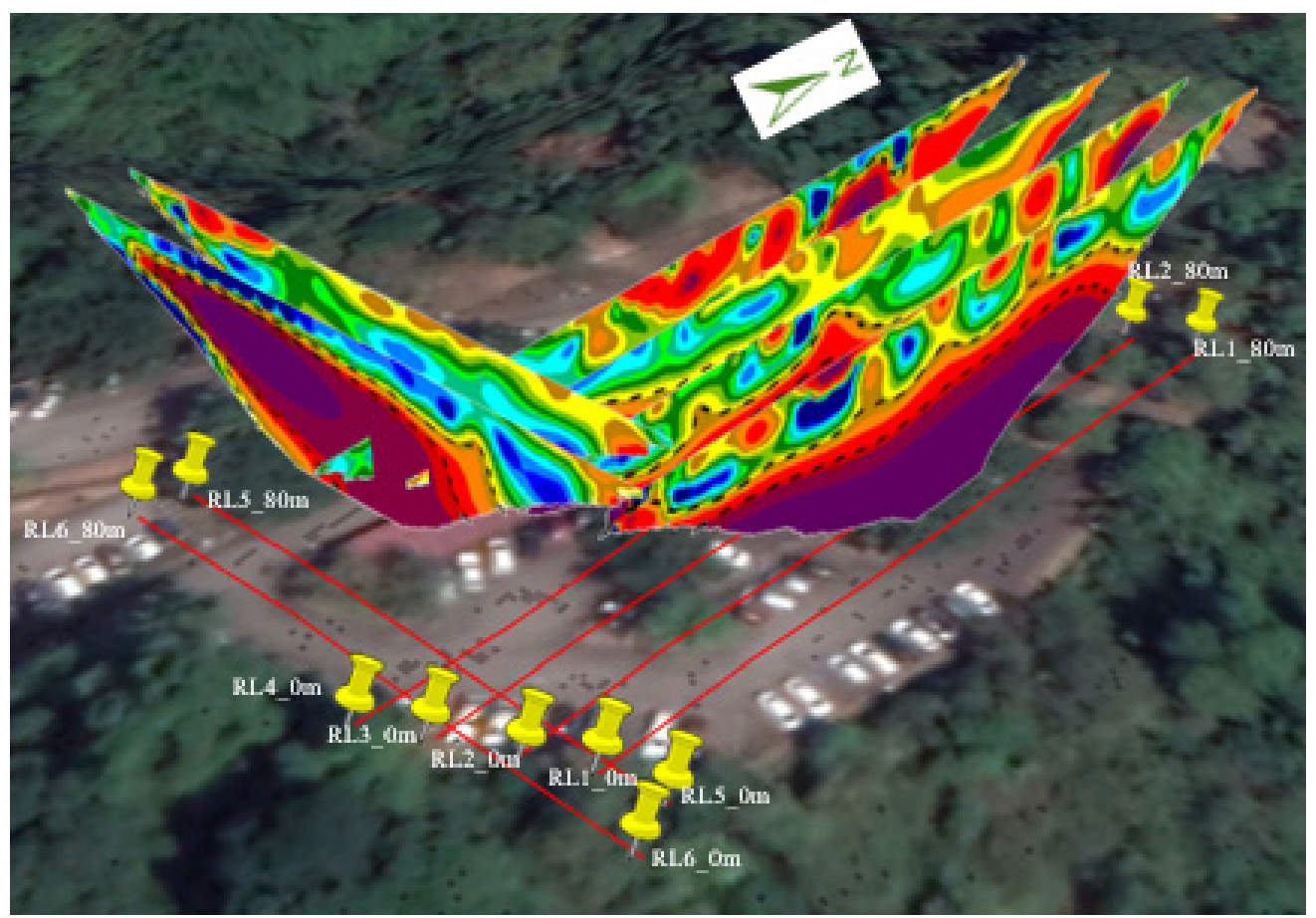

Fig. 6 Overlay of the six inverse resistivity models in google map.

of the area. Based on the borehole record, $1 \mathrm{~m}$ to about $15 \mathrm{~m}$ depth of the subsurface is basically residual soil, mainly silt and or clayey sand (Nordiana et al., 2014). The resistivity result shows a saturated zone inferred to be part of the residual soil (silt and clay) with resistivity value $<600 \Omega$.m at depth $<15 \mathrm{~m}$ in most of the profiles. This reflects the lithological information provided by the borehole log. Moreover, underlying the residual soil is the highly weathered granitic rock and beneath lies the bedrock with resistivity value of $600 \Omega$.m to $1200 \Omega$.m and $>1200 \Omega$.m respectively.

Furthermore, the six inverse resistivity profile were placed according to their acquisition coordinate position with the goal of providing a holistic view of the subsurface (Fig. 6). It is observed that the saturated zone (low resistivity zones) is more concentrated at the East and Southern parts of the study area. The saturated zone is attributed to the high water content of the residual soil (Loke et al., 2013). All the saturated zones correspond to the areas with surface cracks.

\section{CONCLUSION}

Microgravity and electrical resistivity imaging techniques have been successfully applied to investigate the subsurface condition of the study area. The low amplitude negative gravity anomaly zone (- 1.50 to $-1.37 \mathrm{rad})$ as depicted on the tilt angle derivative map corresponds to the saturated zone with low resistivity $(<150 \Omega$.m) as shown on the inverse resistivity models. This, in turn, corresponds with the residual soil (silt and clay) formation given by the borehole record which is characterized by expansion and contraction with the rise and fall in moisture content. With these properties of the residual soil, it can be inferred that the surface cracks experienced on the asphalt are largely due to the expansion and contraction process. Based on the findings of this study, the area is devoid of subsidence triggering features such as cavities or voids. Hence the area is said to be relatively stable with no likely occurrence of serious subsidence. However, the area cannot support heavy load due to the expansive and contractive nature of its subsurface soil. Therefore, grouting or other soil stabilization processes are recommended before the establishment of any structure within the area.

\section{ACKNOWLEDGEMENT}

The authors wish to thank Universiti Sains Malaysia (USM) for providing the Fundamental Research Grant Scheme entitled Development of 2-D Linear Inversion Algorithm from Geophysical Approach for Soil or Rock Characteristics (203/PFIZIK/6711663) and (RUI) Grant entitle Integrated geophysical characterization of geothermal exploration and strategy for sustainable use of geothermal resources with account no. 1001/PFIZIK/8011110. The first author expresses appreciation to the Federal University of Lafia and Tertiary Education Trust Fund (TetFund), Nigeria, for financial support.

\section{REFERENCES}

Abidin, H.Z., Andreas, H., Gumilar, I., Sidiq, T.P. and Fukuda, Y.: 2013, Land subsidence in coastal city of Semarang (Indonesia): Characteristics, impacts and causes. Geomat. Nat. Haz. Risk, 4, 3, 226-240.

DOI: $10.1080 / 19475705.2012 .692336$ 
Ahmad, F., Yahaya, A.S., Farooqi, M.A. and Tebal, N.: 2006, Characterization and geotechnical properties of Penang residual soils with emphasis on landslides. Am. J. Environ. Sci., 2, 4, 121-128.

Akin, U., ŞERİFOĞLU, I.B. and Duru, M.: 2011, The use of tilt angle in gravity and magnetic methods. Mineral Res. Expl. Bull, 143, 1-12.

Ali, M.M., Ahmad, F., Yahaya, A.S. and Farooqi, M.A.: 2011, Characterization and hazard study of two areas of Penang island, Malaysia. Hum. Ecol. Risk Asses., 17, 4, 915-922. DOI: $10.1080 / 10807039.2011 .588156$

Bell, F.G., Donnelly, L.J., Genske, D.D. and Ojeda, J.: 2005, Unusual cases of mining subsidence from Great Britain, Germany and Colombia. Environ. Geol., 47, 5, 620-631. DOI: 10.1007/s00254-004-1187-9

Cao, Y., Wei, Y. N., Fan, W., Peng, M. and Bao, L.: 2020, Experimental study of land subsidence in response to groundwater withdrawal and recharge in Changping District of Beijing. PLoS ONE, 15, 5, 1-17.

DOI: 10.1371/journal.pone.0232828

Cárdenas-Soto, M., Escobedo-Zenil, D., Tejero-Andrade, A., Nava-Flores, M., Vidal-García, M.C. and Natarajan, T.: 2020, Exploring near-surface subsidence over a rehabilitated underground mine through ambient seismic noise tomography in combination with other geophysical methods. Near Surf. Geophys., 18, 5, 483-495. DOI: $10.1002 /$ nsg. 12108

Ghazifard, A., Akbari, E., Shirani, K. and Safaei, H.: 2017, Evaluating land subsidence by field survey and DInSAR technique in Damaneh City, Iran. J. Arid Land, 9, 5, 778-789. DOI: 10.1007/s40333-017-0104-5

Hackney, R.: 2020, Gravity, data to anomalies. In: H.K. Gupta (Ed.), Encyclopedia of Solid Earth Geophysics, 1-10. Springer International Publishing. DOI: 10.1007/978-3-030-10475-7_78-1

Hussain, Y., Uagoda, R., Borges, W., Nunes, J., Hamza, O., Condori, C., Aslam, K., Dou, J. and Cárdenas-Soto, M.: 2020, The potential use of geophysical methods to identify cavities, sinkholes and pathways for water infiltration. Water, 12, 8, 2289. DOI: $10.3390 / \mathrm{w} 12082289$

Ibraheem, I.M., Gurk, M., Tougiannidis, N. Tezkan, B.: 2018, Subsurface investigation of the Neogene Mygdonian basin, Greece using magnetic data. Pure Appl. Geophys., 175, 8, 2955-2973. DOI: $10.1007 / \mathrm{s} 00024-018-1809-\mathrm{x}$

Kong, B.T.: 1994, Engineering properties of granitic sons and rocks of Penang Island, Malaysia. Geol. Soc. Malays., 35, 69-77.

Li, X. and Götze, H.: 2001, Ellipsoid, geoid, gravity, geodesy, and geophysics. Geophysics, 66, 6, 16601668. DOI: $10.1190 / 1.1487109$

Loke, M.H.: 2018, Tutorial: 2-D and 3-D electrical imaging surveys.

Loke, M.H., Chambers, J.E., Rucker, D.F., Kuras, O. and Wilkinson, P.B.: 2013, Recent developments in the direct-current geoelectrical imaging method. J. Appl. Geophys., 95, 135-156.

DOI: 10.1016/j.jappgeo.2013.02.017

Marschalko, M., Yilmaz, I., Bednárik, M., Kubec, K., Bouchal, T. and Závada, J.: 2012, Subsidence map of underground mining influence for urban planning: An example from the Czech Republic. Q. J. Eng. Geol. Hydrogeol., 45, 2, 231-241. DOI: $10.1144 / 1470-9236 / 11-048$

Martínez-Moreno, F.J., Pedrera, A., Ruano, P., GalindoZaldívar, J., Martos-Rosillo, S., González-Castillo, L.,
Sánchez-Úbeda, J.P. and Marín-Lechado, C.: 2013, Combined microgravity, electrical resistivity tomography and induced polarization to detect deeply buried caves: Algaidilla cave (Southern Spain). Eng. Geol., 162, 67-78.

DOI: $10.1016 /$ j.enggeo.2013.05.008

Nordiana, M.M., Rosli, S. and Nawawi, M.N.M.: 2014, A numerical comparison of enhancing horizontal resolution (EHR) technique utilizing 2D resistivity imaging. Arab. J. Geosci., 7, 1, 299-309.

DOI: $10.1007 / \mathrm{s} 12517-012-0792-2$

Oh, H.J. and Lee, S.: 2010, Assessment of ground subsidence using GIS and the weights-of-evidence model. Eng. Geol., 115, 1-2, 36-48. DOI: $10.1016 /$ j.enggeo.2010.06.015

Pazzi, V., Di Filippo, M., Di Nezza, M., Carlà, T., Bardi, F., Marini, F., Fontanelli, K., Intrieri, E. and Fanti, R.: 2018, Integrated geophysical survey in a sinkholeprone area: Microgravity, electrical resistivity tomographies, and seismic noise measurements to delimit its extension. Eng. Geol., 243, 282-293. DOI: $10.1016 /$ j.enggeo.2018.07.016

Pradhan, B., Abokharima, M.H., Jebur, M.N. and Tehrany, M.S.: 2014, Land subsidence susceptibility mapping at Kinta Valley (Malaysia) using the evidential belief function model in GIS. Nat. Hazards, 73, 2, 10191042. DOI: $10.1007 / \mathrm{s} 11069-014-1128-1$

Pradhan, B. and Lee, S.: 2010, Delineation of landslide hazard areas on Penang Island, Malaysia, by using frequency ratio, logistic regression, and artificial neural network models. Environ. Earth Sci., 60, 5, 1037-1054. DOI: 10.1007/s12665-009-0245-8

Prudhomme, K.D., Khalil, M.A., Shaw, G.D., Speece, M.A., Zodrow, K.R. and Malloy, T.M.: 2019, Integrated geophysical methods to characterize urban subsidence in Butte, Montana, U.S.A. J. Appl. Geophys., 164, 87105. DOI: 10.1016/j.jappgeo.2019.03.004

Saada, S.A.: 2016, Edge detection and depth estimation of Galala El Bahariya Plateau, Eastern Desert-Egypt, from aeromagnetic data. Geomech. Geophys. Geo., 2, 1, 25-41. DOI: 10.1007/s40948-015-0019-6

Salehi, F., Naser, M., Moghaddas, H., Reza, G. and Maryam, L.: 2019, Geological parameters affected land subsidence in Mashhad plain, north-east of Iran. Environ. Earth Sci., 78. DOI: 10.1007/s12665-019-8413-y

Sastry, R.G. and Mondal, S.K.: 2013, Geophysical characterization of the Salna Sinking Zone, Garhwal Himalaya, India. Surv. Geophys., 34, 1, 89-119. DOI: $10.1007 / \mathrm{s} 10712-012-9206-\mathrm{y}$

Scintrex Ltd.: 2012, CG-5 Scintrex autograv system operation manual. Part 1 \# 867700 revision 8. Scintrex Limited, Concord.

Smith, D.L.: 1986, Application of the pole-dipole resistivity technique to the detection of solution cavities beneath highways. Geophysics, 51, 3, 833-837.

Yassin, R.R., Fatihah, R., Samsudin, M. and Taib, H.: 2013, Application of electrical resistivity tomography (ERT) and arial photographs techniques in geo hazard assessment of karst features in constructing sites in Perak, Peninsular Malaysia. J. Environ. Earth Sci., 3, 9, 91-125.

Zheng, M., Fukuyama, K. and Sanga-Ngoie, K.: 2013, Application of InSAR and GIS techniques to ground subsidence assessment in the Nobi Plain, Central Japan. Sensors (Switzerland), 14, 1, 492-509. DOI: $10.3390 / \mathrm{s} 140100492$ 